\title{
Does Online Real-Time Quiz "Kahoot!" Increase Students' Knowledge and Enthusiasm During Laboratory Activity Lesson?
}

\author{
Afiat Berbudi ${ }^{1, *}$, Maghfira Dwivani Rahmaputri ${ }^{2}$, Kurnia Wahyudi $^{3}$, Julia Ramadhanti $^{4}$ \\ ${ }^{1}$ Department of Biomedical Sciences, Parasitology Division, Faculty of Medicine, Padjadjaran University, Indonesia \\ ${ }^{2}$ Undergraduate Program, Faculty of Medicine, Padjadjaran University, Indonesia \\ ${ }^{3}$ Department of Public Health, Faculty of Medicine, Padjadjaran University, Indonesia \\ ${ }^{4}$ Department of Biomedical Sciences, Pharmacology and Therapy Division, Faculty of Medicine, Padjadjaran University, Indonesia
}

Received June 26, 2020; Revised August 5, 2020; Accepted August 28, 2020

\section{Cite This Paper in the following Citation Styles}

(a): [1] Afiat Berbudi, Maghfira Dwivani Rahmaputri, Kurnia Wahyudi, Julia Ramadhanti , "Does Online Real-Time Quiz "Kahoot!" Increase Students' Knowledge and Enthusiasm During Laboratory Activity Lesson?," Universal Journal of Educational Research, Vol. 8, No. 10, pp. 4716 - 4722, 2020. DOI: 10.13189/ujer.2020.081041.

(b): Afiat Berbudi, Maghfira Dwivani Rahmaputri, Kurnia Wahyudi, Julia Ramadhanti (2020). Does Online Real-Time Quiz "Kahoot!" Increase Students' Knowledge and Enthusiasm During Laboratory Activity Lesson?. Universal Journal of Educational Research, 8(10), 4716 - 4722. DOI: 10.13189/ujer.2020.081041.

Copyright $\bigcirc 2020$ by authors, all rights reserved. Authors agree that this article remains permanently open access under the terms of the Creative Commons Attribution License 4.0 International License

\begin{abstract}
Background: Teaching medical parasitology in the form of teacher-centered lectures requires innovation using the help of the latest digital technology to increase the effectiveness of the teaching. Realtime quiz Kahoot in an online platform is chosen in this study as a method combined with lecture because it is simple and flexible. Objective: This research analyzes the effect of applying Kahoot in increasing students' knowledge and enthusiasm for learning medical parasitology. Method: In total, 277 medical students were recruited to participate in this study, consisting of 181 females and 96 males. The research was a randomized controlled trial. The increase of knowledge was measured analytically using secondary data from pre-test and post-test during laboratory activity and the student's enthusiasm was described using primary data from questionnaires given to students that attend the Kahoot session. Participants are undergraduate medical students in Faculty of Medicine, Universitas Padjadjaran in the odd semester and divided into two groups: control and treatment. Results: There was no significant difference between the control group and the treatment group in knowledge increase, with a difference in median 0.055 , confidence interval $95 \%(-0.126 ; 0.014), \mathrm{p}=0.162$. The total average of the percentage of the participants scoring agrees statements in the primary data that showed student's enthusiasm was $68.85 \%$. Conclusion: The analysis of
\end{abstract}

student's knowledge of medical parasitology after using Kahoot shows no significant difference reflecting that there was no effect in using Kahoot for increasing knowledge in the teaching-learning process. However, the descriptive analysis of questionnaires shows that student's enthusiasm was relatively high (68.65\%) after using Kahoot in class.

Keywords Students' Enthusiasm, Kahoot, Teaching Method, Medical Parasitology, Education

\section{Introduction}

Research shows that lecture-based learning that is teacher-centered is now thought of as an ineffective method in transferring information and causing the listeners to become passive $[1,2]$. As the advancement of technology [3] progresses, the younger generation prefers and is accustomed to using technology as a helping tool in all aspects of their life, including studying [4]. Therefore, teachers must adapt to the changes that are happening. In realizing this, teachers can apply the latest education method based on technology to increase student's understanding of learning material $[5,6]$.

In general, laboratory activity in medical school was 
done by giving a manual to students and giving a lecture afterward [7]. Making the class to be more interactive can improve a teacher-centered class [8]. In recent years, there are several new methods used by educators in giving a lesson and one of them is by using online quiz and gamification [9] because it can increase student's enthusiasm [10]. Kahoot is used in the education process as a tool to give online quiz in the form of games (gamification) [11].

Kahoot is easy to be applied to educators or students $[12,13]$, and it can be combined with lectures in order to increase student's participation, attention and wellbeing to the course given [12]. Enthusiasm is one factor that can increase effectivity in teaching-learning process. There is information retention to a person's memory by learning, which can increase his or her knowledge [14]. For these reasons, this research aimed to observe the effectiveness of using Kahoot in increasing knowledge and enthusiasm of students during teaching-learning process.

\section{Materials and Methods}

The design of the study is a randomized controlled trial. The research was conducted in the laboratory activity of Faculty of Medicine, Universitas Padjadjaran, Indonesia. It was performed during the Gastrointestinal System rotation with the topic of medical parasitology, in odd semester of 2019. The data used were secondary data obtained from pre-test and post-test during the lecture of medical parasitology and then these data were analyzed as knowledge variable. The student's enthusiasm toward the use of Kahoot was obtained from primary data through questionnaires.

The participants of this study were medical student undergraduates of Faculty of Medicine, Universitas Padjadjaran in the fifth semester. The inclusion criteria for knowledge measurement were the score of students who attended the medical parasitology laboratory activity. Scores of students who only took pre-test or post-test and took the Kahoot Session one time were excluded from the analysis. The analysis was conducted by comparing the pretest and posttest score of students that were treated with Kahoot game activity and students having no Kahoot session during their laboratory activity. On the other hand, the inclusion criteria for enthusiasm were students who attended the medical parasitology medic laboratory activity with Kahoot session and were willing to participate after giving informed consent. The scheme of inclusion and exclusion during the study can be seen in Appendix figure 1.

The number of participants was determined by total sampling. Participants were divided into six groups according to their lab activity schedule, which is Monday, Wednesday and Friday and on each day, there were 2 sessions, morning and afternoon. Randomization at the group level was done by the resource person during the lab activity to determine the control group and the treatment group. Treatment group (I) was the group that received additional treatment, they did the pre-test using google forms, received lecture, used Kahoot and then did the post-test. Control group (II) was the group that did not do Kahoot and only took pre-test and post-test with a lecture in between. The randomization result was lab activity group on Monday morning, Friday morning and Friday afternoon was assigned as the control group and the group on Monday afternoon, Wednesday morning and Wednesday afternoon was assigned as the treatment group. In the end, the treatment group with Kahoot session was asked to fill in questionnaires after informed consent. The scheme of the research design can be seen in Appendix figure 2.

To measure the enthusiasm of students, questionnaires adapted from the research "The Wear Out Effect of A Game-Based Student Response System" (Alf Inge Wang, 2014) [15] were distributed to collect the data. The questionnaire consisted of 11 statements and was distributed using Google forms platform. Before the questionnaire was used, the questionnaire was tested for validity and reliability test among the students of the Faculty of Medicine, Universitas Padjadjaran.

The quiz for Kahoot session and online pre-test and post-test were made by the resource person of the medical parasitology laboratory activity.

\section{Ethical clearance}

This study was approved by the Ethics committee of Universitas Padjadjaran. (Number: 1087 / UN6.KEP / EC / 2019).

\section{Data analysis}

The collected data of pre-test and post-test score were analyzed using Wilcoxon Rank Sum test to compare the level of knowledge between groups of students who have Kahoot session (treatment group) with students who have no Kahoot session (control group). The students' enthusiasm was descripted from the questionnaires result. IBM SPSS software version 20 and R 3.6.1. were used to help the statistical analysis. All statistical tests were carried out at the significance level $\mathrm{p}<0.05$.

\section{Results}

From the statistical analysis, the results are as follows:

\section{Kahoot game activity session during laboratory activity did not increase students' knowledge}

The number of participants that meet the inclusion and exclusion criteria to analyze the knowledge variable was 277 students and was divided into 2 groups. The control group consisted of 136 students and the treatment group 
consisted of 141 students.

It can be concluded from the statistical analysis that there was no significant difference between the score in both the treatment and the control group $(p=0.162)$. The data analysis of pre-test and post-test is shown in Figure 1.

\section{Enthusiasm toward the use of Kahoot was high}

As mentioned in the materials and methods section, to obtain students' feedback regarding their experience during Kahoot session, the questionnaires were given.
There were 24 students who were unwilling to fill the questionnaire in the treatment group and therefore the response rate from the descriptive analysis of the questionnaire was $82,9 \%$.

Even though there was no significant difference between the score of the test, analysis of student's enthusiasm among 117 students toward the use of Kahoot showed a good level of enthusiasm. The result of the descriptive analysis of the agreement of the participants is shown in Table 1.

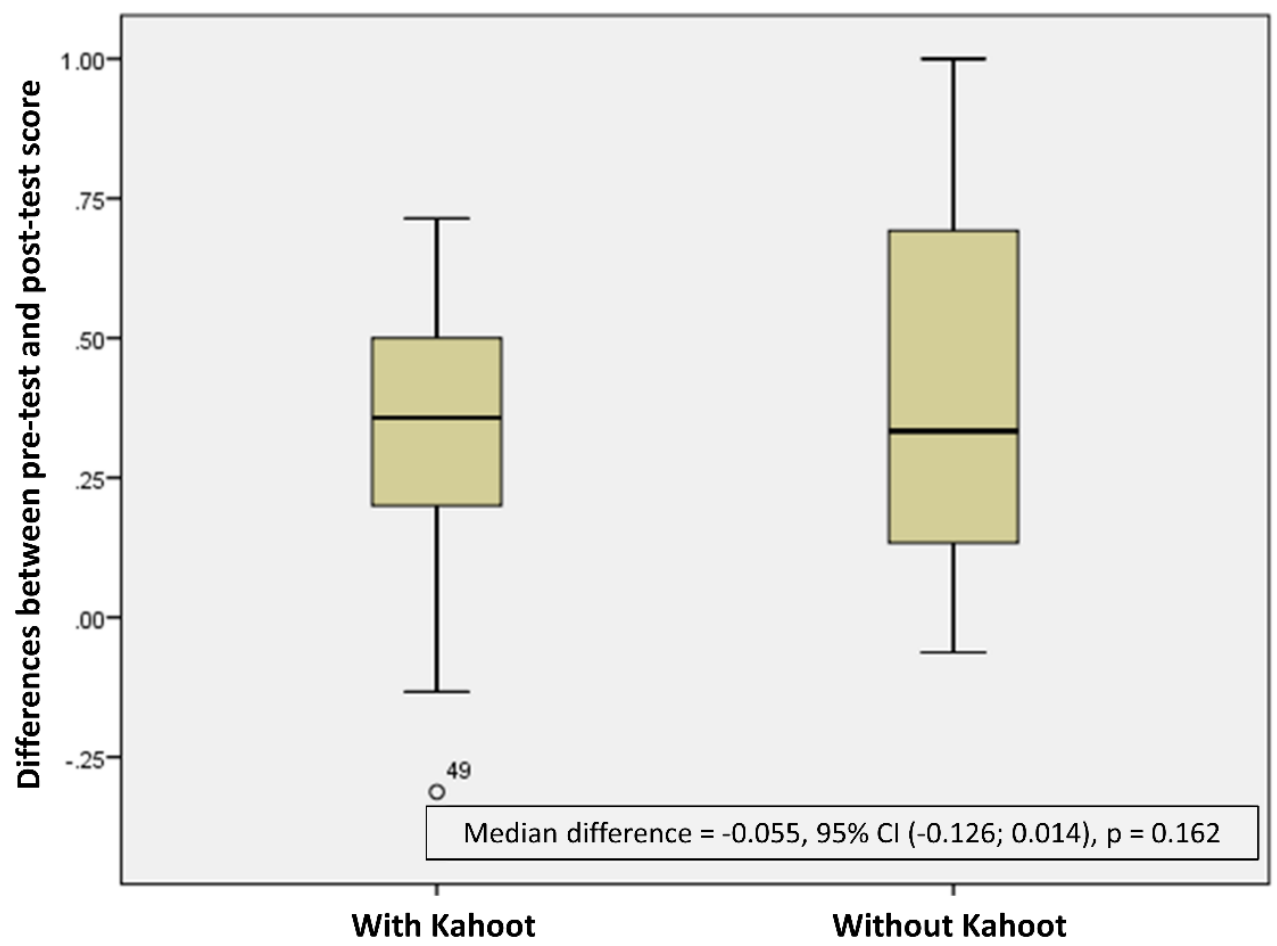

Figure 1. Statistical analysis of differences between students' pre-test and post-test score

Table 1. Questionnaire data analysis

\begin{tabular}{|c|c|c|c|c|}
\hline No & Statement & Disagree & Neutral & Agree \\
\hline 1 & I can easily use Kahoot with my cellular phone & $1,72 \%$ & $5,17 \%$ & $93,10 \%$ \\
\hline 2 & I interact with other players about the quiz material when Kahoot session has finished & $4,31 \%$ & $27,59 \%$ & $68,10 \%$ \\
\hline 3 & I enjoy competing with other players & $10,34 \%$ & $20,69 \%$ & $68,97 \%$ \\
\hline 4 & I enjoy playing Kahoot in the same room as the other players & $3,45 \%$ & $16,38 \%$ & $80,17 \%$ \\
\hline 5 & I concentrate more when playing with other people & $12,93 \%$ & $37,93 \%$ & $49,14 \%$ \\
\hline 6 & I am actively involved with the course material during Kahoot session & $1,72 \%$ & $29,31 \%$ & $68,97 \%$ \\
\hline 7 & I am emotionally involved to the game during Kahoot session & $17,24 \%$ & $40,52 \%$ & $42,24 \%$ \\
\hline 8 & I enjoy playing Kahoot & $2,59 \%$ & $17,24 \%$ & $80,17 \%$ \\
\hline 9 & I hope Kahoot can be used in other learning topic & $6,90 \%$ & $20,69 \%$ & $72,41 \%$ \\
\hline 10 & I understand better and I like the topic given after Kahoot session & $7,76 \%$ & $39,66 \%$ & $52,59 \%$ \\
\hline 11 & I learn something about the material given in Kahoot session & $4,31 \%$ & $16,38 \%$ & $79,31 \%$ \\
\hline & Total average & $6,66 \%$ & $24,69 \%$ & $68,65 \%$ \\
\hline
\end{tabular}




\section{a. User-friendliness in using Kahoot platform}

The first statement in Table 1 (I can use a cellular phone to access Kahoot easily) was asked to evaluate the difficulty in using Kahoot platform in cellular phones. Overall, students felt it was easy to access Kahoot using their cellular phones with the score of agreement 93,10\%.

\section{b. The class dynamic was increased during Kahoot session}

The class dynamic can be seen from the response to the second statement to the fifth statement about the interaction between students, enjoyment during the competition, enjoyment while playing in the same classroom, and the level of concentration during competing with other students. It can be concluded that the class dynamic was increased. The percentage of agreement in the second statement (I interact with other students about the quiz material when Kahoot session has finished) showed a score that was not relatively high, which was $68,10 \%$. Several respondents did mention that they interacted with other students during the Kahoot session, when each question has been finished, and the score was shown.

The third statement (I enjoy competing with other players) showed a high frequency of agreement $(69,87 \%)$. The majority of the respondents enjoy the competitive environment so that many of them felt motivated to get the highest score. However, there were also several respondents who did not enjoy this and felt pressured, especially when they were not able to answer the quiz. The fourth statement (I enjoy playing Kahoot in the same classroom with other students) reached a very high agreement percentage $(80,17 \%)$. Respondents felt happy when they could see the other players' scores on the main screen.

In the fifth statement (I concentrate more when playing with other students), the agreement percentage was relatively low $(49,14 \%)$. The feedback from the students mentioned that the reason why their concentration was not affected because the time to answer the quiz was relatively short.

\section{c. Student's involvement in the course material}

Statement 6 and 7 in Table 1 concerning the student's active participation. Statement 6 (I am actively involved with the course material during the Kahoot session) showed a relatively good percentage of agreement $(68,97 \%)$. Meanwhile, statement 7 (I am involved emotionally to the game during the Kahoot session) showed an agreement percentage $(42,4 \%)$ that is not very different from the neutral agreement percentage (40,52\%) with the difference of $1,72 \%$. From the students' feedback, they felt emotionally involved when the other players had higher scores than what they had, or when the students had a desire to put themselves in the top 5 ranks so that their name would be shown in the leaderboard. Several students were neutral about the statement because they think Kahoot was just a game and they could accept if the scores were not as they expected.

\section{d. Enjoyment in using Kahoot and the material given}

Statement 8 to 11 in Table 1 were given in order to see how Kahoot influences student's motivation during giving material. The three statements showed a high percentage of agreement, especially statement 8 (I enjoy playing Kahoot) and statement 9 (I hope Kahoot can be used in other activity) with the agreed percentage of $80,1 \%$ and $72,41 \%$, respectively. This is because players considered learning with Kahoot was not monotonous and hoped that Kahoot is used in certain materials, for example, material that was difficult and boring.

On the other hand, the agreement percentage to statement 10 (I understand better and like the topic that was given after the Kahoot session) only reach 52,59\%. The low percentage of agreement to that statement was because students felt that the Kahoot session was not enough to make them feel more interested in a certain topic. Giving quiz through gamification needs to be supported with interesting lectures. The last statement, statement 11, mentioned if the students felt they had learned or gained something about the material that was given in the quiz during Kahoot session. The questionnaire showed $79,31 \%$ of the students agreed to the statement. The students felt that the material given became clearer to them because the main important points of the material were included in the quiz. The students can also recall the material beforehand because Kahoot session was allocated at the end of the medical parasitology lab activity before the end of the lecture. By recalling the material, there was a repetition which can improve the memory of students about the material given.

\section{Discussion}

Kahoot is an educational platform based on gamification that has been used by millions of people every month after it was launched in 2013. The advantage of Kahoot is that it is free, it can connect educators and students in a quiz format, discussion panel, and survey. Furthermore, the quiz maker can add videos, images, or even music and they can adjust the time given for each question. Furthermore, the students only need to access the Kahoot site without an obligation to download it in their cellular phones and the results are shown in the main screen and in each cellular phone [16].

According to research in neurobiology, there are several methods that can be done to maximize the result of an educational process, which is the knowledge gained [17]. Amongst them are: repetition, reward and reinforcement, active involvement and visualization. Repetition can reactivate the information stored in the brain and result in 
memory reinforcement. If someone is excited and enjoys a learning process, the brain will give a reward signal [19] that will then reinforce or enhance memorization [20]. Visualization aspect will help the brain to elaborate a complex subject so that it will increase the effectivity of studying $[19,21]$. Active involvement is when someone can learn information based on the experience in presenting something directly, instead of just learning theory, will increase confidence or reflection of what needs to be improved [22]. These aspects can be seen in the use of Kahoot in lecture. Kahoot allocated at the end of medical parasitology lab activity allows students to repeat material before the session ends. Kahoot also gives reward to players in the top 5 ranks by showing the highest scores on the main screen. Reward in the form of compliment is often given by other players and teachers to the students with the highest scores. Kahoot provides interesting visualization by using many different colors and teachers can add images or videos in the quiz. These functions show that Kahoot is a suitable tool to be used as an additional session in lectures.

Based on the overall questionnaire results in Table 1, the total average of the agreement percentage is quite high, which is $68,65 \%$. From this result, it can be concluded that the students' enthusiasm increased when they used Kahoot for learning. The level of knowledge of the students was also increased, whether the students were in the control group or in the treatment group. This result is in accordance with Oroujlu and Vahedi study which showed that students' enthusiasm, involvement, and willingness to participate will influence the quality of discussion and study so that it will increase the possibility of gaining knowledge [23].

This study has several limitations, one of them is that group randomization was only done at group level that was adjusted with the schedule of lab activity of each group. To increase the quality of the data, randomization can be performed at daily level or even at individual level to get data with better quality. The participants of the research were limited only to students who attended lab activity with the topic of medical parasitology. It is suggested to increase the number of the study population in future studies, in other topics or other educational activities besides lab activity. The groups after the first lab activity (Monday morning) possibly had known the questions in the pre-test or post-test beforehand and it is better to use entirely new questions for different days or all evaluation is performed in the same time to reduce bias.

\section{Conclusions}

Kahoot application that is based on gamification is an optional method for learning and it is good to be used as a combination with the lecture in the educational process of the medical parasitology lab activity. This method is in line with the need for today, which is an implementation of the latest technology to education in order to increase effectiveness. From this study, it was shown that knowledge increase was not significantly different statistically, however, the students' enthusiasm after using Kahoot in lab activity was high.

\section{Conflict of Interest}

The authors declare that this research is not funded by any organization including Kahoot.

\section{Acknowledgments}

The authors would like to thank the Undergraduate Program and the Academic Evaluation Unit of Faculty of Medicine, Universitas Padjadjaran. 


\section{Appendix}

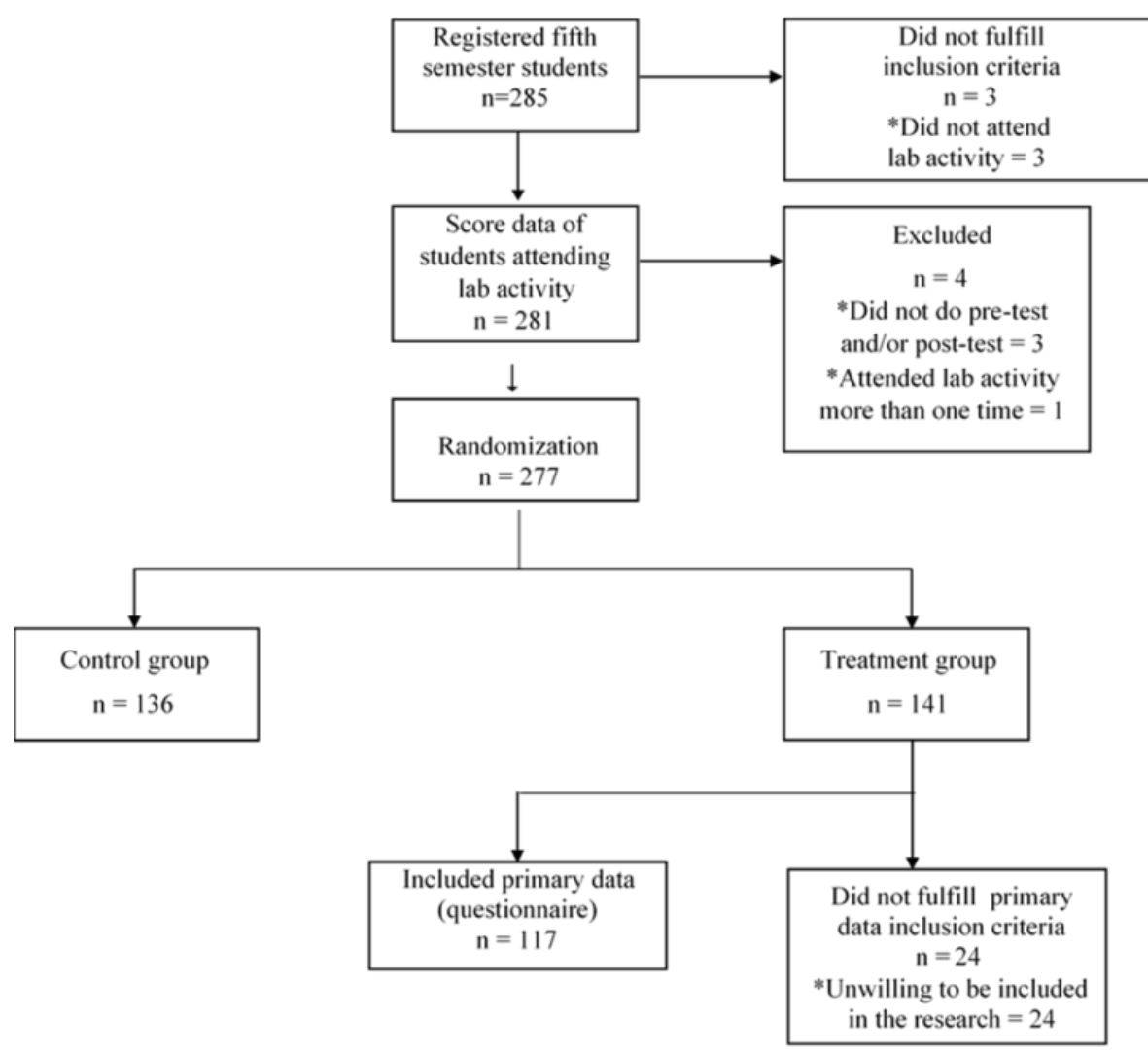

Figure 1. Schematic diagram of study design

Control group

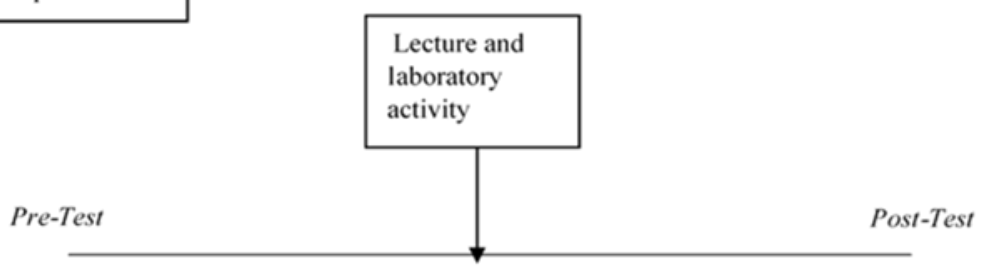

Treatment group

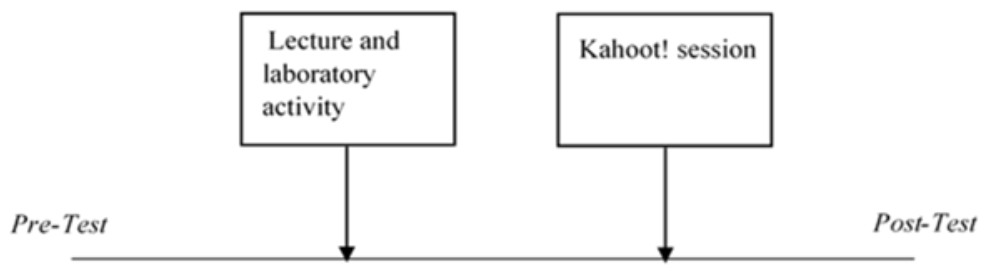

Figure 2. Schematic diagram of experimental setup 


\section{REFERENCES}

[1] Chan LK. Giving Lecture. In: Teaching Anatomy. 2015. p. 61-71.

[2] Lochner L, Wieser H, Waldboth S, Mischo-Kelling M. Combining traditional anatomy lectures with e-learning activities: how do students perceive their learning experience? Int J Med Educ. 2016;7:69-74.

[3] Lin DTA, Ganapathy M, Kaur M. Kahoot! It: Gamification in higher education. Pertanika J Soc Sci Humanit. 2018;26(1):565-82.15

[4] Lister MC, College H. Gamification: The effect on student motivation and performance at the post-secondary level. Issues Trends Educ Technol. 2015;3(2):1-22.

[5] Guardia JJ, Del Olmo JL, Roa I, Berlanga V. Innovation in the teaching-learning process: the case of Kahoot! Horiz. 2019;27(1):35-45.

[6] Glover I. Play as you learn : gamification as a technique for motivating learners. Proc World Conf Educ Multimedia, Hypermedia Telemcommunications [Internet]. 2013;19982008.

[7] Suhoyo Y.Konsep Inovasi Strategi Pendidikan di Institusi Pendidikan Kedokteran. Jurnal Pendidikan Kedokteran Indonesia. 2012;1(2):1-10.

[8] Meguid EA, Collins M. Traditional Vs Interactive. 2017;229-41.

[9] Jabbar A, Gasser RB, Lodge J. Can New Digital Technologies Support Parasitology Teaching and Learning? Trends Parasitol. 2016;32(7):522-30.

[10] Hailikari T, Tuononen T, Parpala A. Students' experiences of the factors affecting their study progress: differences in study profiles. J Furth High Educ. 2018;42(1):1-12.

[11] Hamari J, Koivisto J, Sarsa H. Does Gamification Work? A Literature Review of Empirical Studies on Gamification. Proc 47th Hawaii Int Conerence Syst Sci. 2014; January(6-

9).

[12] Plump CM, LaRosa J. Using Kahoot! in the Classroom to Create Engagement and Active Learning: A Game-Based Technology Solution for eLearning Novices. Manag Teach Rev. 2017;2(2):151-8.

[13] Kuo CL, Chuang YH. Kahoot: Applications and effects in education. J Nurs. 2018;65(6).

[14] Gabryś-Barker D. Success: From failure to failure with enthusiasm. Stud Second Lang Learn Teach. 2015;2:30125 .

[15] Wang AI. The wear out effect of a game-based student response system. 2015;82:217-27. 2014.11.004

[16] Ismail MA-A, Mohammad JA-M. Kahoot: A Promising Tool for Formative Assessment in Medical Education. Educ Med J. 2017;9(2):19-26.

[17] Morris R. Neuroscience in the 21st Century. Neuroscience in the 21st Century. 2012. 2173-2212 p.

[18] Alberini CM. The Role of Reconsolidation and the Dynamic Process of Long-Term Memory Formation and Storage. Front Behav Neurosci. 2011;5(March):1-10.

[19] Friedlander MJ, Andrews L, Armstrong EG, Aschenbrenner C, Kass JS, Ogden P, et al. What Can Medical Education Learn From the Neurobiology of Learning? 2011;86(4):415-20.

[20] Fields HL, Hjelmstad GO, Margolis EB, Nicola SM. Ventral Tegmental Area Neurons in Learned Appetitive Behavior and Positive Reinforcement. Annu Rev Neurosci. 2007;30(1):289-316.

[21] Kawamichi H, Kikuchi Y, Noriuchi M, Senoo A, Ueno S. Distinct neural correlates underlying two- and three-dimensional mental rotations using three-dimensional objects. Brain Res. 2007;1144(1):117-26.

[22] Cabeza R, Ciaramelli E, Olson IR, Moscovitch M. The parietal cortex and episodic memory: An attentional account. Nat Rev Neurosci. 2008;9(8):613-25.

[23] Oroujlou N, Vahedi M. Motivation, attitude, and language learning. Procedia - Soc Behav Sci. 2011;29(2010):994 1000 . 